\title{
SELF-ASSEMBLED CHITOSAN NANOPARTICLES FOR PERCUTANEOUS DELIVERY OF CAFFEINE: PREPARATION, CHARACTERIZATION AND IN VITRO RELEASE STUDIES
}

\section{NIK AMANINA FARHANAH ABU HASSAN, SHARIZA SAHUDIN*, ZAHID HUSSAIN, MUMTAZ HUSSAIN}

Department of Pharmaceutics, Faculty of Pharmacy, Universiti Teknologi Mara, Puncak Alam Campus 42300 Selangor, Malaysia Email: shariza2280@puncakalam.uitm.edu.my

Received: 16 Mar 2018, Revised and Accepted: 16 Jun 2018

\section{ABSTRACT}

Objective: Chitosan (CS)-tripolyphosphate (TPP)-nanoparticles (NPs) have been extensively studied during the past few decades due to their wellrecognized applicability in various fields. The present study attempts to optimise the development of these nanoparticles to enhance the percutaneous delivery of caffeine.

Methods: CS-TPP-NPs were prepared via ionic cross-linking of CS and TPP and were characterized. The influence of several formulation conditions (CS: TPP mass ratio and concentration of caffeine) and process parameters (stirring speed, stirring time and ultra-sonication time) on the colloidal characteristics of CS-TPP-NPs were investigated and the resulting nanoparticles were characterized using scanning electron microscopy (SEM), transmission electron microscopy (TEM), Fourier transform infrared (FTIR) and x-ray diffraction (XRD) analyses. Physicochemical properties, including particle size, zeta potential and polydispersity index (PDI) were examined, and in vitro release studies were conducted to ascertain the release profile of caffeine from the nanoparticles. In addition, the colloidal stability of the prepared NPs was also assessed on storage.

Results: Process parameters appeared to exert a significant effect on the physicochemical characteristics of the CS-TPP-NPs. The CS-TPP-NPs prepared under optimum conditions (CS concentration of $0.2 \mathrm{mg} / \mathrm{ml}$, CS: TPP volume ratio of 25:12 ml, stirred at $700 \mathrm{rpm}$ for $60 \mathrm{~min}$, with 0.97 $\mathrm{mg} / \mathrm{ml}$ caffeine concentration and treatment with low ultra-sonication for $30 \mathrm{~min}$ ) had shown a mean particle size of $\sim 143.43 \pm 1.69 \mathrm{~nm}$, zeta potential of $+43.13 \pm 1.10 \mathrm{mV}$, PDI of $\sim 0.30 \pm 0.01$. A drug loading capacity and encapsulation efficiency of $48.89 \%$ and $60.69 \%$, respectively, were obtained. Cumulative release study for drug-loaded CS-NPs was significantly ( $p<0.001$, paired t-test) higher ( $58.7 \%$ caffeine released) compared to control formulation (41.5\% caffeine released) after $72 \mathrm{~h}$. Stability studies conducted for 28 d showed that caffeine-loaded CS-NPs degraded much quicker when stored at $25{ }^{\circ} \mathrm{C}$ than $4{ }^{\circ} \mathrm{C}$. It was also noted that caffeine-loaded CS-NPs in the freeze-dried form were unstable as the surface charge of nanoparticles dropped from positive zeta potential to- $3.55 \mathrm{mV}$ within $2 \mathrm{~d}$ at $4{ }^{\circ} \mathrm{C}$ and at $25{ }^{\circ} \mathrm{C}$, surface charge dropped to-3.16 mV within $14 \mathrm{~d}$ of the experiment.

Conclusion: Chitosan (CS)-tripolyphosphate (TPP)-nanoparticles (NPs) appear to be a promising strategy to achieve sustained percutaneous delivery of caffeine.

Keywords: Chitosan nanoparticles, Drug delivery, Caffeine, Ionic gelation

(C) 2018 The Authors. Published by Innovare Academic Sciences Pvt Ltd. This is an open access article under the CC BY license (http://creativecommons.org/licenses/by/4.0/) DOI: http://dx.doi.org/10.22159/ijap.2018v10i4.25947

\section{INTRODUCTION}

Androgenic alopecia is a common disorder of scalp hair follicles, effecting men and women, resulting in the gradual thinning and increased loss of hair from the scalp. In men, the degree of hair loss follows a well-defined pattern, with a receding hairline and thinning of the crown, usually going on to develop completely bald areas. Women tend to show a generalized thinning of the crown, but rarely leading to complete baldness. A number of genetic and environmental factors are thought to contribute to androgenic alopecia, however, dihydrotestosterone, (DHT), has been found to be the effector hormone for this type of hair loss, causing a continuous shortening of hair growth cycle (anagen phase) and eventually miniaturized, hair follicles [1].

Caffeine is well known as a mild stimulant of the central nervous system where it is transported with blood after its absorption in the stomach and small intestine [5]. Consumption of caffeine can reduce drowsiness and restoring alertness, cognitive function, particularly vigilance, mood and perception of fatigue [6]. Caffeine has high biological activity [2] and an ability to penetrate the skin barrier [3, $4]$, hence is being increasingly used in cosmetics applications. For example, caffeine has been used as an active compound in anticellulite products because it prevents excessive accumulation of fat in cells $[7,8]$. It stimulates the degradation of fats during lipolysis through inhibition of the phosphodiesterase activity [9]. In addition, caffeine has potent antioxidant properties. Studies revealed that use of caffeine in the formulation of sunscreen cosmetics raises its protective effect against UV radiation, reduces the formation of free radicals in skin cells and could be useful in preventing UV-induced skin cancers $[10,11]$. Caffeine has been shown to demonstrate beneficial effects on androgenic alopecia [12], due to an influence on hair growth mechanisms. Caffeine act as a phosphodiesterase inhibitor, increasing cAMP levels in cells, counteracting the effects of the DHT hormone and therefore stimulating cell metabolism to promote hair growth [12].

Chitosan nanoparticles have been widely investigated as drug carriers, with the potential to improve bioavailability from the skin [13], enhanced efficacy [14] and the ability to achieve sustain drug release [15]. Minoxidil loaded in chitosan nanoparticle [32] for example has been utilized to achieve sustain drug release about twice more than previous studies using microparticles [16]. In addition, nanoparticles have shown the potential for delivering drugs via the follicles $[17,18]$. The particles can aggregate in the follicular opening and penetrate along the follicular duct when nanoparticles containing active ingredients are applied onto the skin surface. As a result, the active ingredients can be delivered deep into the skin and into the systemic circulation by using nanoparticles for therapeutics aim. Chitosan is a biodegradable polymer, thus presents an advantage in pharmaceutical and cosmetic applications since it can completely be eliminated from the body by natural metabolic pathways [20]. Chitosan is obtained by partial deacetylation of chitin. The amino group in chitosan has a pKa value of $\sim 6.5$, thus, chitosan is positively charged and soluble in acidic to a neutral solution. Ionic gelation method has been extensively used in the preparation of chitosan nanoparticles as it has numerous advantages such as preparation of small size and compact structured particles [21], use of aqueous media [22], and control of colloidal characteristics of the nanoparticles by the variation of 
formulation and process parameters [23]. The method involves ionic cross-linking between cations of chitosan and anion such as sodium tripolyphosphate (TPP) [24]. As reported by Calvo et al., positively charged nanoparticles are formed through inter-and intra-crosslinking of the amino groups $\left(-\mathrm{NH}^{3+}\right)$ of chitosan with negatively charged phosphate groups (-PO ${ }^{4-}$ [ [24]. According to Huang et. al and Yang et. al, the particle size distribution and zeta potential of nanoparticles greatly depends on the mixing procedure of chitosan and TPP and their stoichiometry, as well as chitosan and TPP concentration $[25,26]$.

In this present work, TPP is used as a cross-linker in the preparation of chitosan nanoparticles loaded with caffeine. The effects of stirring rate, CS: TPP volume ratio and the effect concentration of drugs on to optimized the nanoparticles were examined by characterization of the mean diameter size of particles, PDI and zeta potential. The resulting nanoparticles were also characterized using SEM, TEM, FTIR and XRD analyses. In vitro release studies and colloidal stability of the resulting nanoparticles were conducted to evaluate their use as a carrier systems for caffeine.

\section{MATERIALS AND METHODS}

\section{Materials}

Chitosan (CS, deacetylation degree of $85 \%$ and low molecular weight), sodium tripolyphosphate (TPP), phosphate buffered saline (PBS), and caffeine, M. wt $194.19 \mathrm{~g} / \mathrm{mol}$ were purchased from Sigma-Aldrich Co. Ltd (Malaysia). Acetic acid glacial (Grade $\mathrm{AR}, \mathrm{CH}_{3} \mathrm{COOH}, \mathrm{M}$. Wt $60,05 \mathrm{~g} / \mathrm{mol}$ ) was obtained from Friendemann Schmidt. High-performance liquid chromatography (HPLC)-grade acetonitrile was obtained from Fischer Scientific Korea Ltd (Seoul, Korea). All other chemicals used were of analytical grade.

\section{Preparation of unloaded CS-NPs and caffeine-loaded CS-NPs}

Nanoparticles (NPs) were prepared by inducing the gelation of chitosan solutions with crosslink agent, sodium tripolyphosphate (TPP) [28]. 0.2\% low molecular weight CS solution was prepared in $1 \%$ acetic acid while $0.1 \%$ TPP was dissolved in distilled water. CSNPs were spontaneously formed upon addition of TPP into CS solution. Caffeine was dissolved in the $0.1 \%$ TPP solution. Caffeineloaded CS-NPs was formed when TPP containing drug solution was added drop-wise into $25 \mathrm{ml}$ of CS solution under magnetic stirring for $30 \mathrm{~min}$ at room temperature. The resulting caffeine-loaded CSNPs were subjected to ultra-sonication process for a few minutes. The caffeine-loaded CS-NPs were then separated from their suspension by ultracentrifugation at $30,000 \mathrm{rpm}, 25^{\circ} \mathrm{C}$ for $30 \mathrm{~min}$ and subsequently lyophilized (Scanvac Cool Safe 110, Chemoscience, Thailand) at $-90^{\circ} \mathrm{C}$ for $24 \mathrm{~h}$.

\section{Nanoparticles characterization}

\section{Size, zeta potential and PDI}

The resulting pellets co-loaded NPs after ultracentrifugation were collected and suspended in distilled water. The average size, PDI and the zeta potential was determined using "Zetasizer Nano ZS" (Malvern Instrument, UK) equipment. The measurements of samples were done in triplicates.

\section{Encapsulation efficiency and loading capacity}

The resulting supernatant was filtered and analyzed using a HPLC validated method. Various standard solutions of caffeine were prepared and subjecting to reversed phase HPLC.

The effective efficiency (EE \%) and loading capacity (LC \%) were measured corresponding to standard calibration curves. The effective efficiency (EE \%) was calculated using the equation below.

$$
\begin{aligned}
& \mathrm{EE} \%=\frac{[\mathrm{Q} \text { theoretical-Qobtained }]}{\text { Qtheoretical }} \times 100 \\
& \mathrm{LC} \%=\left[\frac{\mathrm{Q}_{\text {theoretical }} \mathrm{Q}_{\text {obtained }}}{\mathrm{Q}_{\text {lyophilized }}}\right] \times 100 \quad(2)
\end{aligned}
$$

Where $Q_{\text {theoretical }}$ was the amount of caffeine initially added to prepare chitosan nanoparticles, Qobtained was the quantified amount of caffeine and $\mathrm{Q}_{\text {lyophilized }}$ was lyophilized caffeine-loaded nanoparticles.

\section{SEM and TEM analysis}

The morphology of nanoparticles and size distribution was observed using scanning electron microscope (FEI Quanta 200 SEM) and transmission electron microscope (Hitachi H-8100 TEM). The lyophilized caffeine-loaded CS-NPs was dispersed in acetone solution and sonicated for approximately $15 \mathrm{~min}$. For SEM, caffeineloaded CS-NPs in acetone solution were spread on a glass plate and dried at room temperature. For TEM, caffeine-loaded CS-NPs in acetone solution was dropped on a copper grid and dried at room temperature. The dried caffeine-loaded CS-NPs were then coated with gold and placed under observation stage and images were observed under, at 10,000 to 100,000 magnifications.

\section{Fourier transform infrared spectroscopy (FT-IR) and X-ray} powder diffraction (XRD) analysis

The chemical structure of CS, unloaded CS-NPs and caffeine-loaded CS-NPs were scanned using an FT-IR spectrophotometer (Spectrum 100; Perkin Elmer, USA). Briefly, a small quantity (2-3) mg of CS was mixed with $78 \mathrm{mg}$ potassium bromide $(\mathrm{KBr})$ and compressed to form a transparent pellet using a hydraulic press. A similar procedure was used to prepare transparent pellets of unloaded CSNPs and caffeine-loaded CS-NPs. Finally, the resulting pellets were scanned in transmission mode in a spectral region of $4000-400 \mathrm{~cm}^{-1}$ using a resolution of $4 \mathrm{~cm}^{-1}$ and 32 co-added scans. The crystalline or amorphous nature of CS, unloaded CS-NPS and drug-loaded CSNPs were confirmed by using X-ray diffractometer (Shidmazu, XRD6000X, Japan). All the samples were scanned from 0 to 120 .

\section{Drug release studies}

CS-NPs loaded with caffeine and $5 \mathrm{ml}$ PBS solution ( $\mathrm{pH}$ 7.4) were added into a dialysis sac (MWCO: 0.5-1.0 kDA) and was placed in $100 \mathrm{ml} \mathrm{PBS}$ at $37^{\circ} \mathrm{C}$ and maintained under water bath, shaken at 200 $\mathrm{rpm}$. The analysis was performed in triplicates for each sample. At specific time intervals, $3 \mathrm{ml}$ medium was taken out and then replaced with fresh PBS. The concentration of released caffeine was determined by HPLC analysis.

\section{Stability studies}

A standard amount of nanoparticles was suspended in PBS solution (pH 7.4) and stirred for 1 hour. All samples was placed in a tube and covered with aluminum foil. Each sample of caffeine loaded CS-NPs were kept separately at $4{ }^{\circ} \mathrm{C}$ and $25{ }^{\circ} \mathrm{C}$ for $28 \mathrm{~d}$. Samples were analyzed at predetermined time intervals of $0,1,3,5 \mathrm{~d}$ and the every week after for up to one month. For each time interval, the average size, PdI and zeta potential of the sample were measured.

\section{HPLC analysis}

The concentration of caffeine was quantified by using reversedphase HPLC method. A reverse-phase C18 column (Shimadzu, 4.6 $\mathrm{mm} \times 150 \mathrm{~mm}, 5 \mu \mathrm{m}$ ) is used. The mobile phase used in this analysis consists of water/acetonitrile mixture at ratio 35:65 $(\mathrm{v} / \mathrm{v})$. The volume of sample injected into the liquid chromatography is $10 \mu \mathrm{l}$ with flow rate of $1.0 \mathrm{ml} / \mathrm{min}$. UV detection is performed at $285 \mathrm{~nm}$. The linearity is measured from the calibration curve of standard solutions containing 0.1-1.0 $\mathrm{mg} / \mathrm{ml}(\mathrm{n}=10)$ of caffeine. The precision and accuracy of this method is expressed as coefficient of variation $(\% \mathrm{CV})$ and relative standard error (\% E) in accordance to FDA guidelines.

\section{Statistical analysis}

All data are presented as mean \pm standard deviation. Data were analyzed with either paired t-tests or independent t-test and ANOVA, followed by a Tukey's post-hoc analysis. For the analysis of particle size, zeta potential, EE, and LC of NPs, a p-value of less than 0.05 was considered to indicate a significant difference. For the data obtained from ex vivo permeation, drug skin retention, and skin thickness, a pvalue of less than $0.001 * * *$ was considered to indicate a significant difference. 


\section{RESULTS AND DISCUSSION}

\section{Particle size, PDI and zeta potential}

The effects of magnetic stirring speed on particle size, PDI and zeta potential are summarized in fig. 1 (A, B and C). As shown in fig. 1A, the particle size of CS-NPs decreased from $617.43 \mathrm{~nm}$ to $411.27 \mathrm{~nm}$ as the speed of stirring was increased from $300 \mathrm{rpm}$ to $700 \mathrm{rpm}$ at constant time of stirring. The size of particles is expected to reduce with increasing agitation [27]. Sufficient stirring can accelerate the dispersion of TPP in CS solution and the increased shear force helps to narrow size distribution [28]. $700 \mathrm{rpm}$ speed of stirring was observed to improve mixing and create a more uniform environment for NPs formation, therefore contributing to a smaller average particles size.

As for PDI and zeta potential, both increased with increasing stirring speed. However the observed changes were not significant.

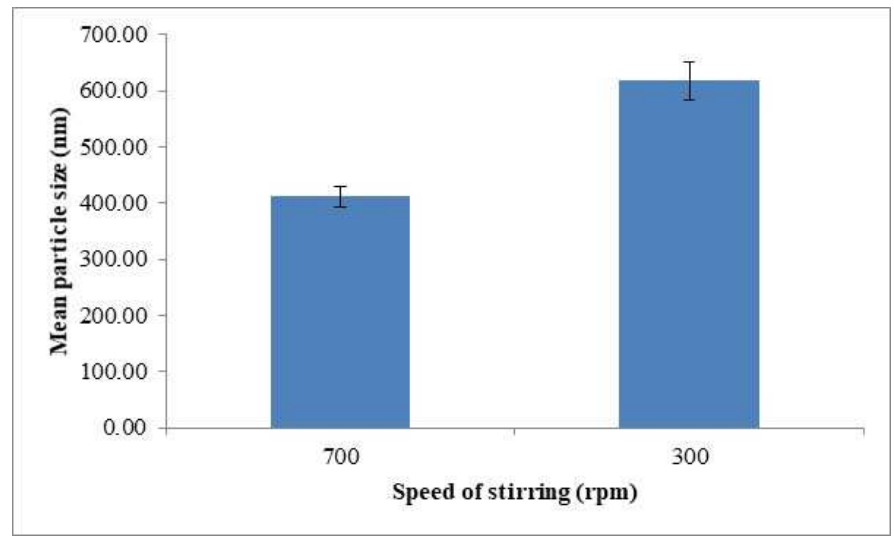

A

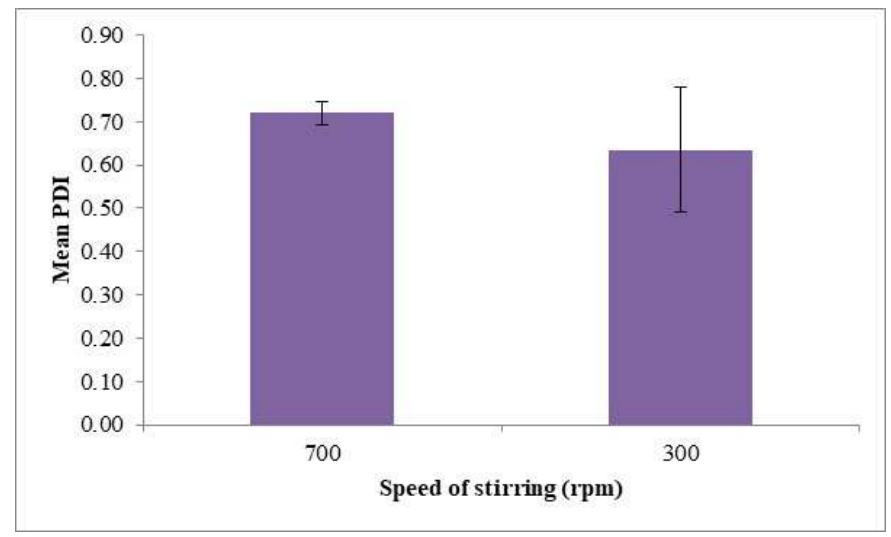

B

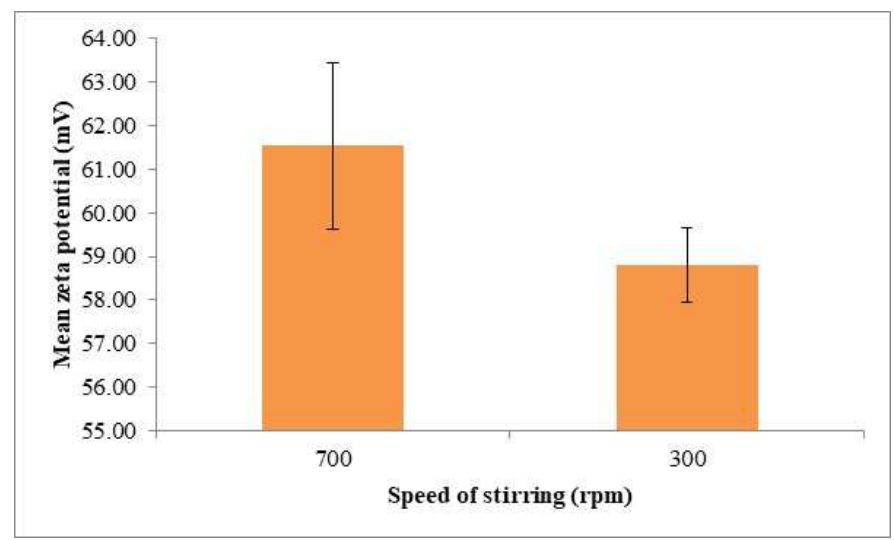

Fig. 1: Mean profile of effect of magnetic stirring on physicochemical properties of CS-NPs. A. Effect on particle size; B. Effect on PDI; C. Effect on zeta potential. (mean $\pm S D, n=3$ )

Stirring time has also been shown to have a significant effect on the particle size. The effect of stirring time on particle size was observed for four different durations of time; $15,30,60$ and 120 min (fig. 2). The resulting data indicates the influence of stirring time, revealing a gradual decrease in the mean particle size from $421.60 \pm 3.47$ to $319.30 \pm 2.31 \mathrm{~nm}$, when stirring was increased from 15 to $60 \mathrm{~min}$. This may be due to an improved dispersion of TPP in chitosan solution at longer stirring times, as the increased shear 
force helps to narrow the dispersity index. However, when the stirring time was increased to $120 \mathrm{~min}$, the mean particle size of NPs was seen to increase to $489.70 \pm 1.71 \mathrm{~nm}$. Nie and co-workers
[29] demonstrated that an increase in the stirring time encourages agglomeration and particle growth, resulting in an increased mean particle size.
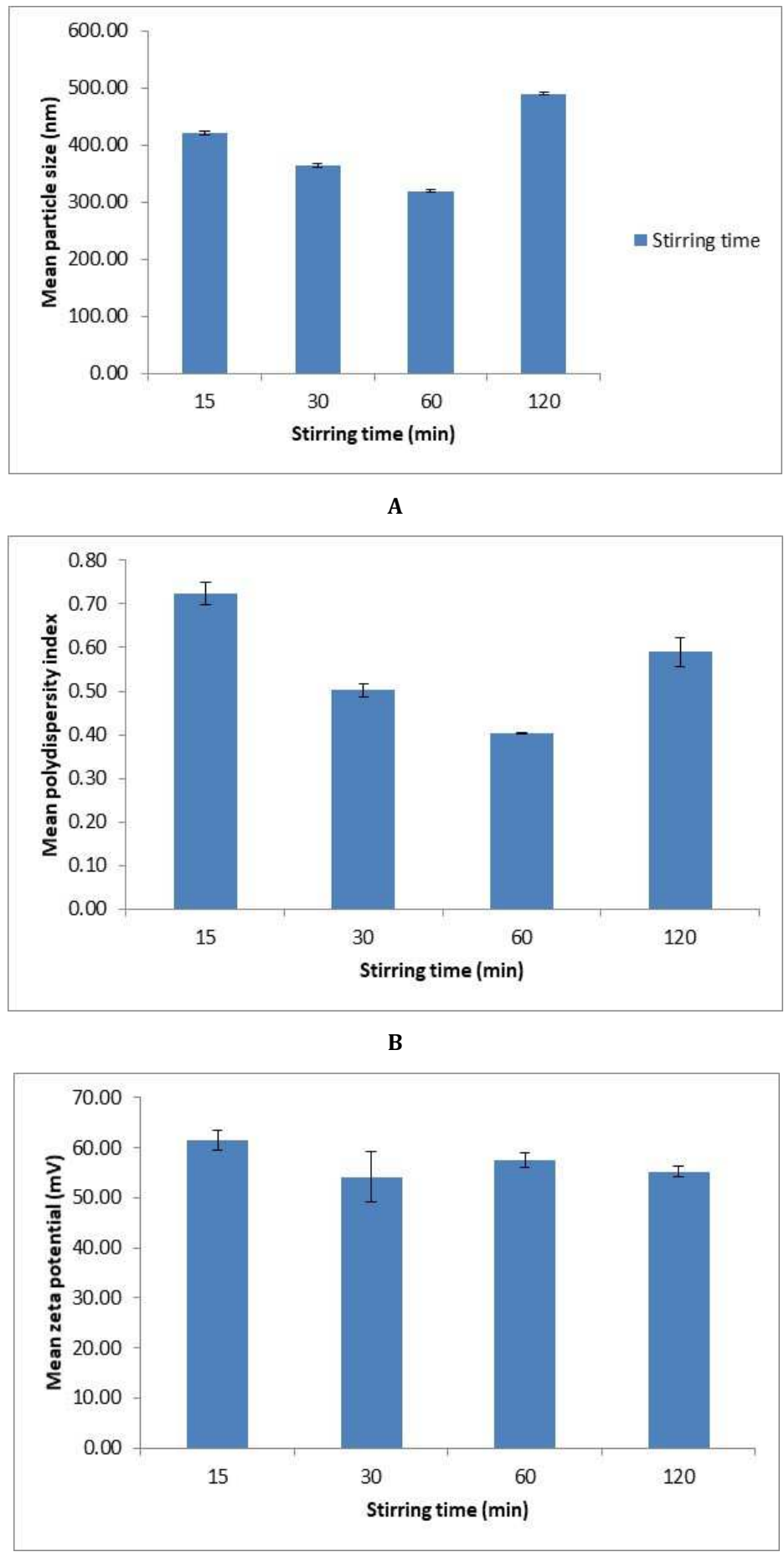

Fig. 2: Mean profile of effect of stirring time on physicochemical properties of CS-NPs, A. Effect on particle size; B. Effect on PDI; C. Effect on zeta potential. (mean $\pm S D, n=3)$

The effects of different volume ratios of CS to TPP ranging from $25: 5$ to $25: 15$ on the physicochemical properties of CS-NPs are shown in fig. 3 . When the volume ratio of CS/TPP was increased from 25:5 to 25:10, the particle size and PDI demonstrated an increase from 584 to $650 \mathrm{~nm}$ in size distribution and PDI in the range 0.6 to 0.8 . This indicates a broader nanoparticle size distribution. One possible explanation is that lowering the TPP volume reduces the ability of the system to crosslink, thus lowering the number of nanoparticles produced. Particle size decreases to a value of $352.50 \mathrm{~nm}$ when the volume ratio of CS/TPP is increased to $25: 12$. This narrow particle size distribution suggests a better ionic interaction [30] between CS 
and TPP at this ratio, leading to an enhanced degree of crosslinking. The particle size was then shown to increase to 506.53 $\mathrm{nm}$ with increased in a volume ratio of CS/TPP to 25:15. At higher levels of TPP, a larger particle of nanoparticles was formed most likely due to the repulsion of charges since there were more cations available for reaction.

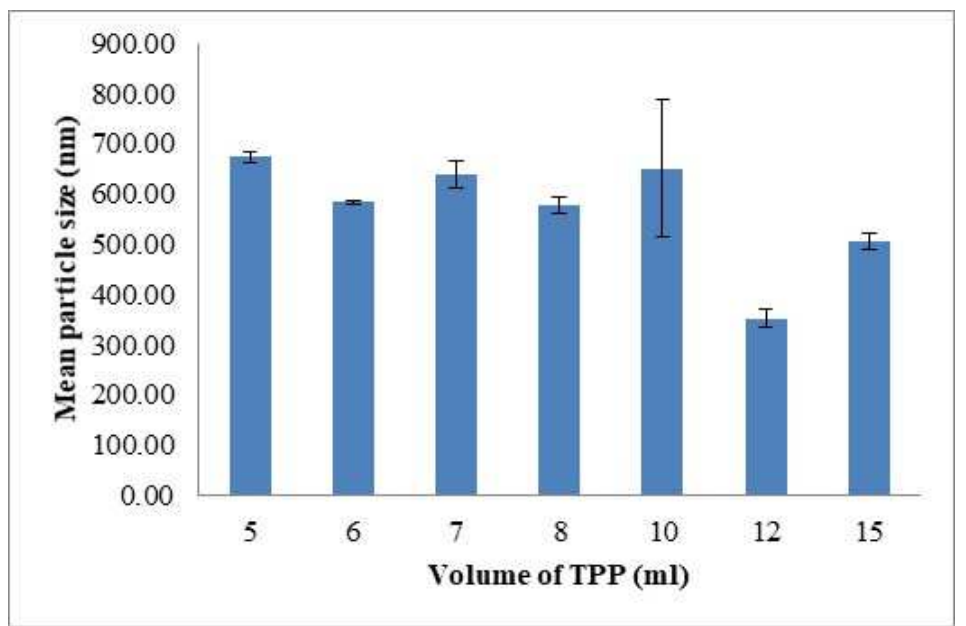

A

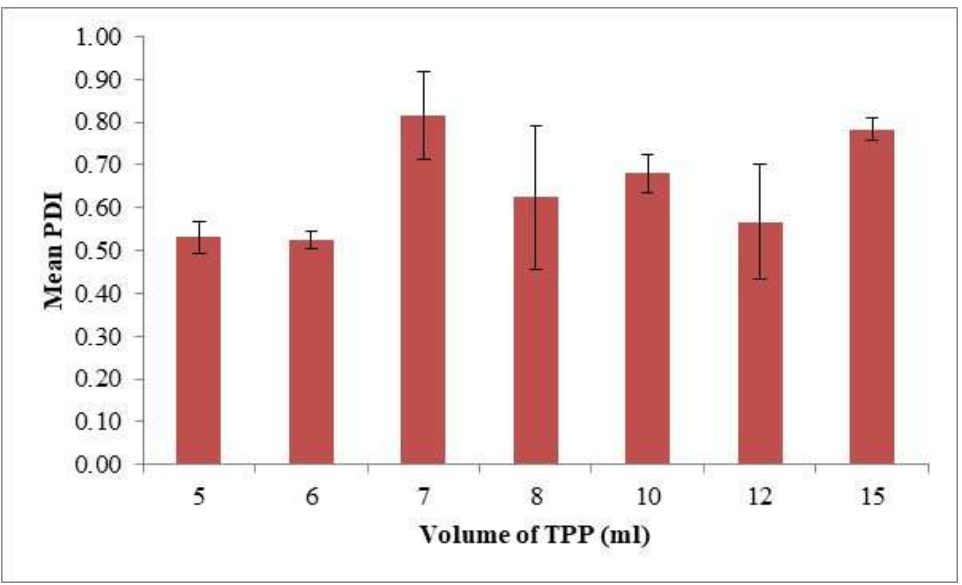

B

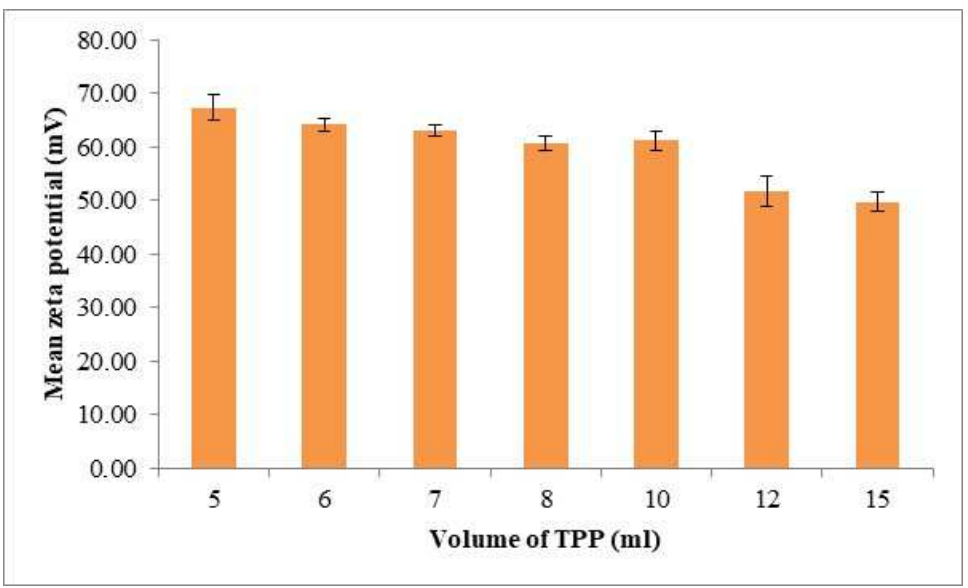

Fig. 3: Mean profile of effect of different volume of TPP added on physicochemical properties of CS-NPs. A. Effect on particle size; B. Effect on PDI; C. Effect on zeta potential. (mean $\pm S D, n=3$ )

To investigate the influence of ultra-sonication on the physicochemical characteristics of NPs, the prepared CS-TPP-NPs dispersion was subjected to low-efficiency ultra-sonic processor over a series of time periods from 5 to $30 \mathrm{~min}$. The resulting data (fig. 4) indicates a linear decrease in the average particle diameter of CS-TPP-NPs with increasing sonication time. The ultrasonication process has been shown to reduce the average of particle size because it can break up the cluster formation of 
nanoparticles and help to scatter the nanoparticles into base fluids [31]. The mean diameter of dispersed NPs is reduced by approximately $50 \%$ after $30 \mathrm{~min}$ of ultra-sonication, from $231.30 \pm 5.80$ to $142.20 \pm 0.61 \mathrm{~nm}$. Moderate use of ultra-sonication could be able to reduce the particle size significantly via the disruption of particle aggregations, however, extensive ultrasonication may cause severe fragmentation of the compact structure of the NPs subjected [28].

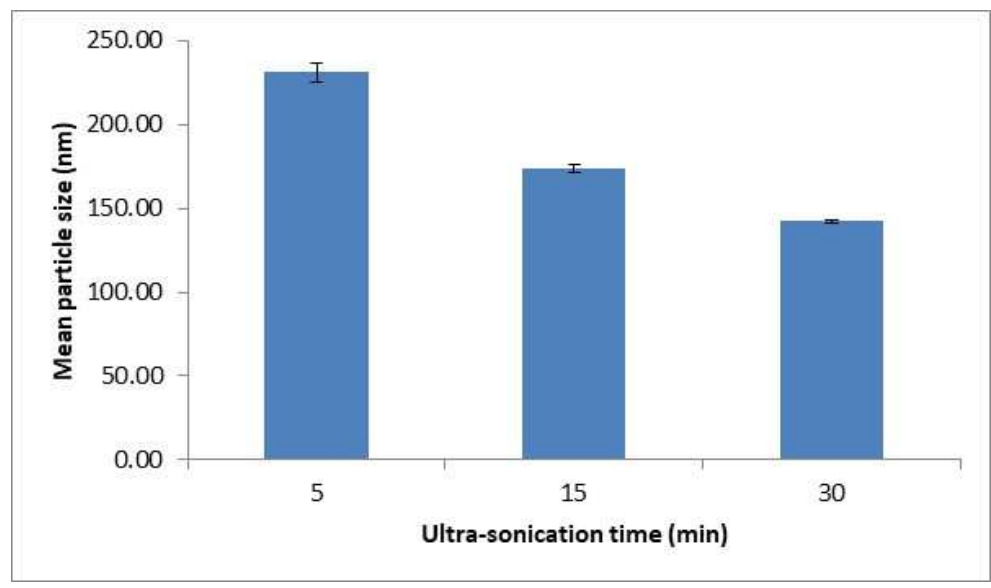

A

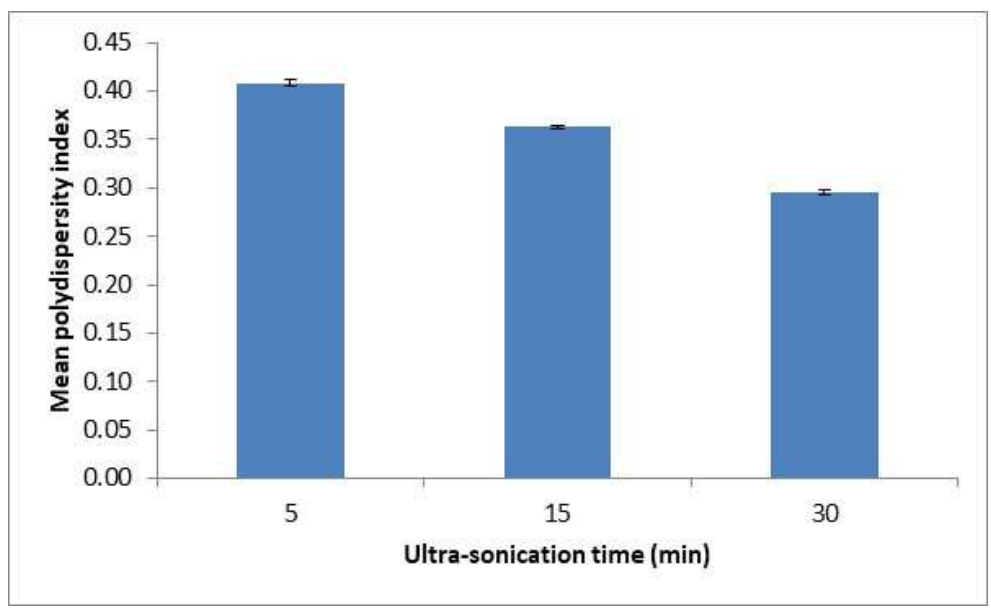

B

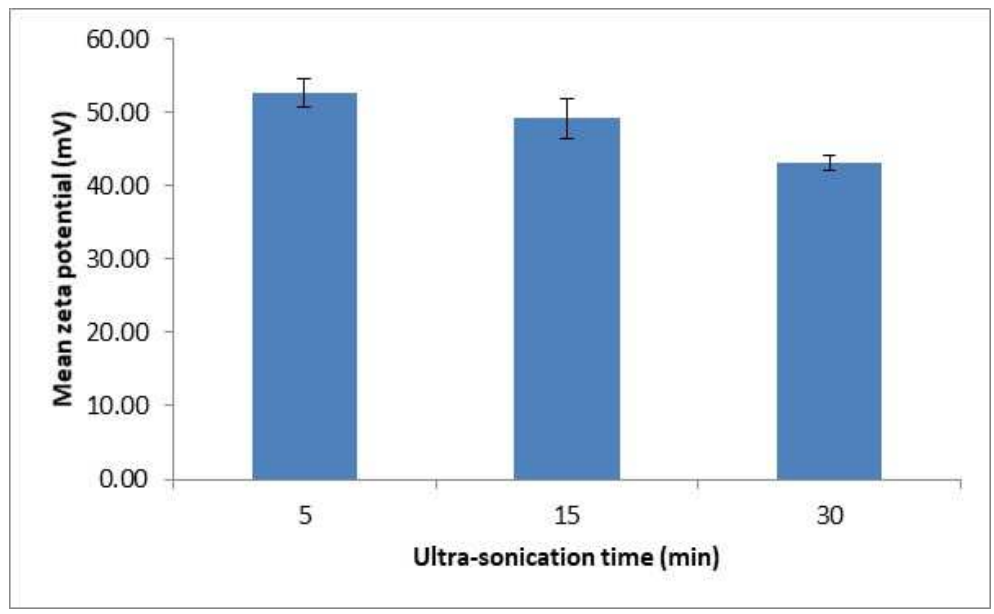

C

Fig. 4: Mean profile of effect of ultra-sonication time on physicochemical properties of CS-NPs. A. Effect on particle size; B. Effect on PDI; C. Effect on zeta potential. (mean $\pm S D, n=3$ )

The effect of different caffeine concentrations on particle size and PDI are summarized in fig. 5. Different formulations of caffeineloaded nanoparticles were prepared by adding a different amount of drug into TPP solution which was then added drop wised into the CS solution. After stirring, these solutions were subjected to ultrasonication for $15 \mathrm{~min}$. As the concentration of caffeine was 
increased from $0.32 \mathrm{mg} / \mathrm{ml}$ to $0.97 \mathrm{mg} / \mathrm{ml}$, the size of particles increased from $143.43 \mathrm{~nm}$ to $230.13 \mathrm{~nm}$, indicating denser complexes forming at higher concentrations, due to the formation of larger self-assembled nanoparticles.
The zeta potentials of unloaded CS-NPs are shown in fig. 1 and 2, and caffeine-loaded NPs in fig. 3. All values are favourably above $+30 \mathrm{mV}$, which ensure the optimum stability of all the suspensions [32].
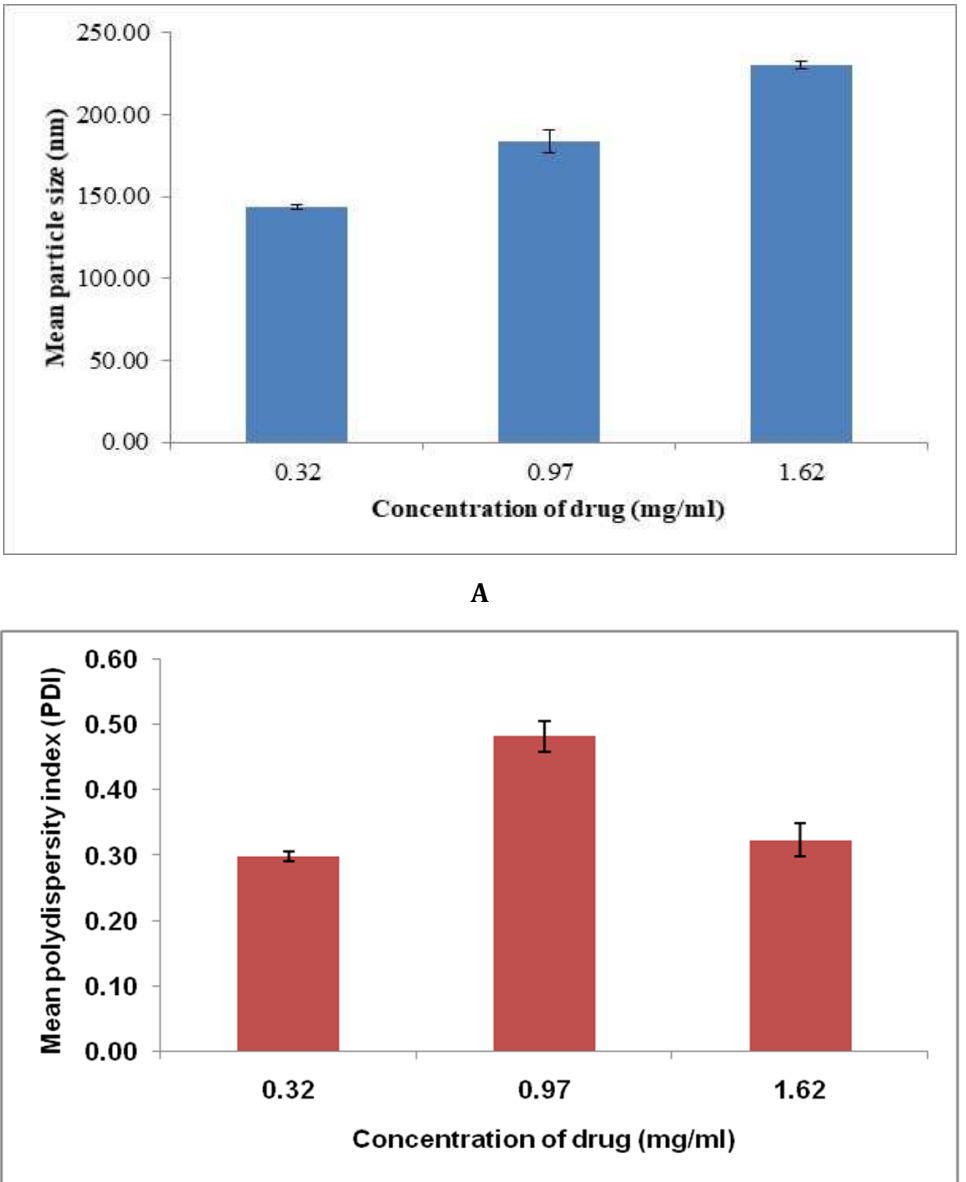

B

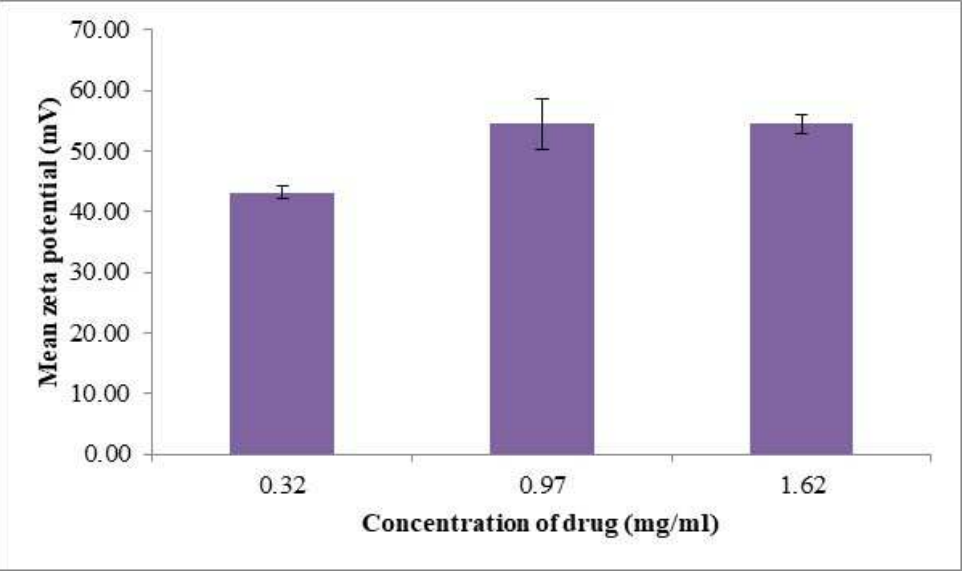

Fig. 5: Mean profile of effect of different concentration of caffeine on physicochemical properties of CS-NPs. A. Effect on particle size; B. Effect on PDI; C. Effect on zeta potential. (mean $\pm S D, n=3$ )

\section{Encapsulation efficiency and loading capacity}

The encapsulation efficiency (EE) and loading capacity (LC) of different formulations were determined and are shown in table 1 . Increasing caffeine concentration from $0.016 \mathrm{mg} / \mathrm{ml}$ to $0.970 \mathrm{mg} / \mathrm{ml}$ in the formulations, results in a higher EE and LC in the range of $3.32 \%-48.89 \%$ and $0.13 \%-60.69 \%$ respectively.
Any further increase in caffeine concentration results in a decrease in EE and LC to $39.10 \%$ and $50.50 \%$ respectively. An increase in the $\mathrm{EE}$ of caffeine may indicate that the reaction mixture becomes more viscous at higher drug concentration, which would tend to increase the forces opposing the extensive incorporation of caffeine inside the polymer matrices and hence reducing the EE caffeine [34]. 
Table 1: Encapsulation efficiency and loading capacity of different concentration of caffeine-loaded CS-NPs formulations (mean \pm SD, $n=3$ )

\begin{tabular}{lll}
\hline Concentration of caffeine $(\mathbf{m g} / \mathbf{m l})$ & EE\% & LC\% \\
\hline 0.016 & 3.32 & 0.13 \\
0.032 & 5.01 & 0.41 \\
0.320 & 33.50 & 16.08 \\
0.970 & 48.89 & 60.69 \\
1.620 & 39.10 & 50.50 \\
\hline
\end{tabular}

\section{Morphological observation}

The morphological characteristics of caffeine-loaded CS-NPs were examined using SEM and TEM analysis and the results are shown in fig. 6 and 7, respectively. The results suggest that caffeineloaded CS-NPs are relatively smooth and spherical with a diameter varying from $50-150 \mathrm{~nm}$. All the NPs from SEM and TEM images were smaller than the hydrodynamic sizes determined by light scattering because of the drying and vacuum process. The variable morphology of caffeine-loaded CS-NPs may be attributed to the variation in the inter-or intra-particulate interaction of caffeineloaded CS-NPs, may contribute to this morphological diversity. Both TEM and SEM micrographs revealed that some particle aggregation may be due to the freezing and drying stress from the freeze-drying process, and this aggregation contributes to the mean particle size $[34,36,40]$.

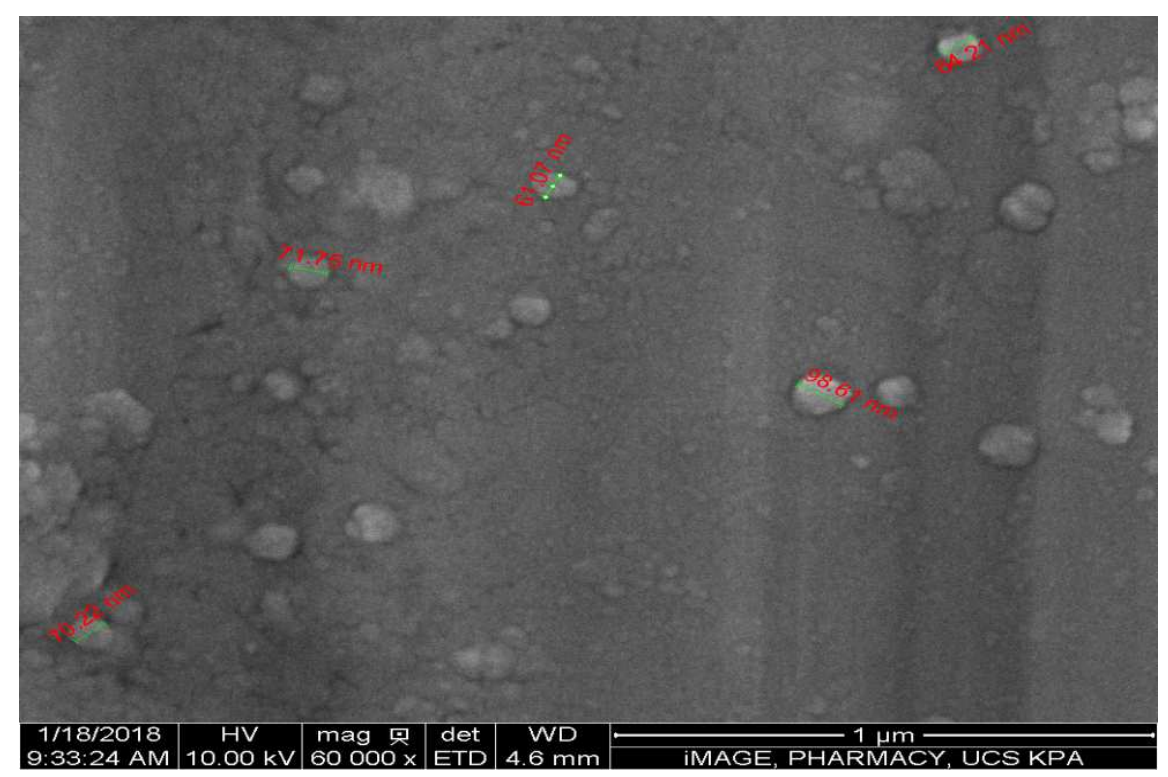

A

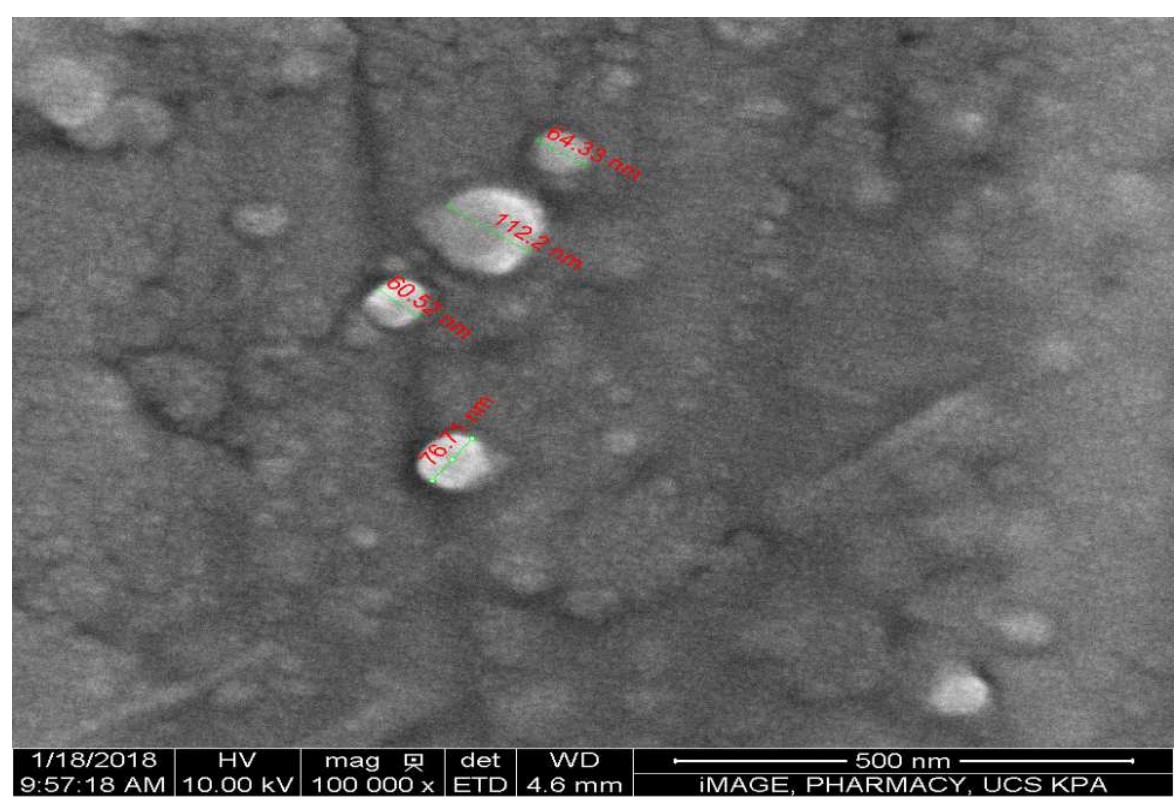

B

Fig. 6: Electron micrographs obtained by SEM for the morphological and size analysis of lyophilized caffeine-loaded CS-NPs. A. 60000 magnification; B. 100000 magnification 


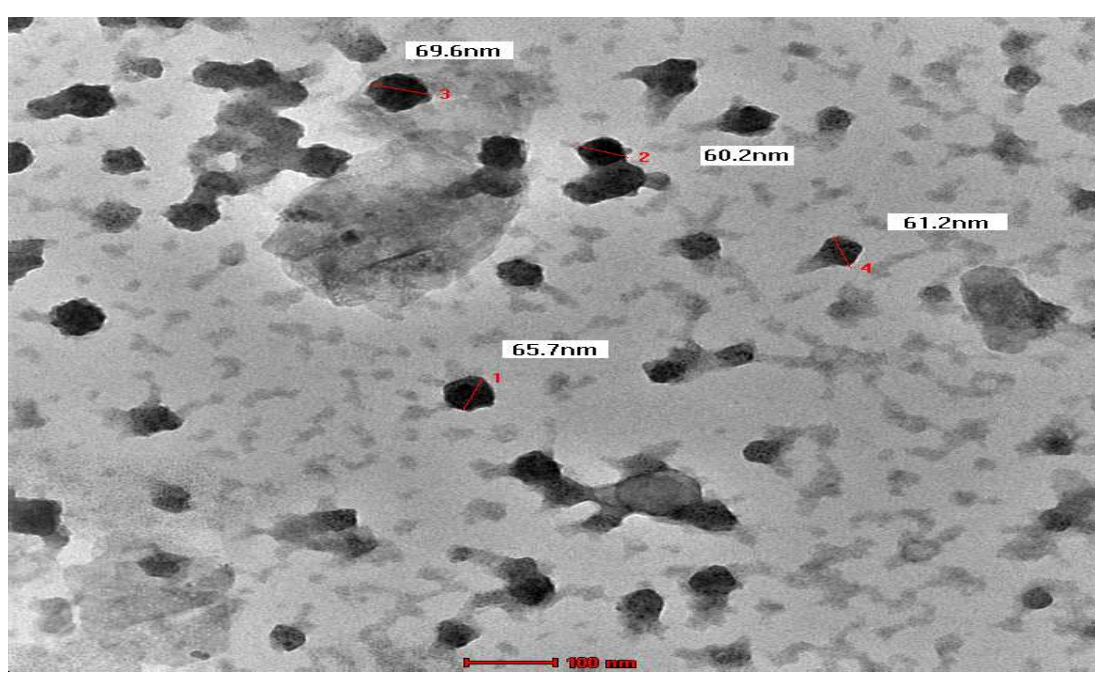

A

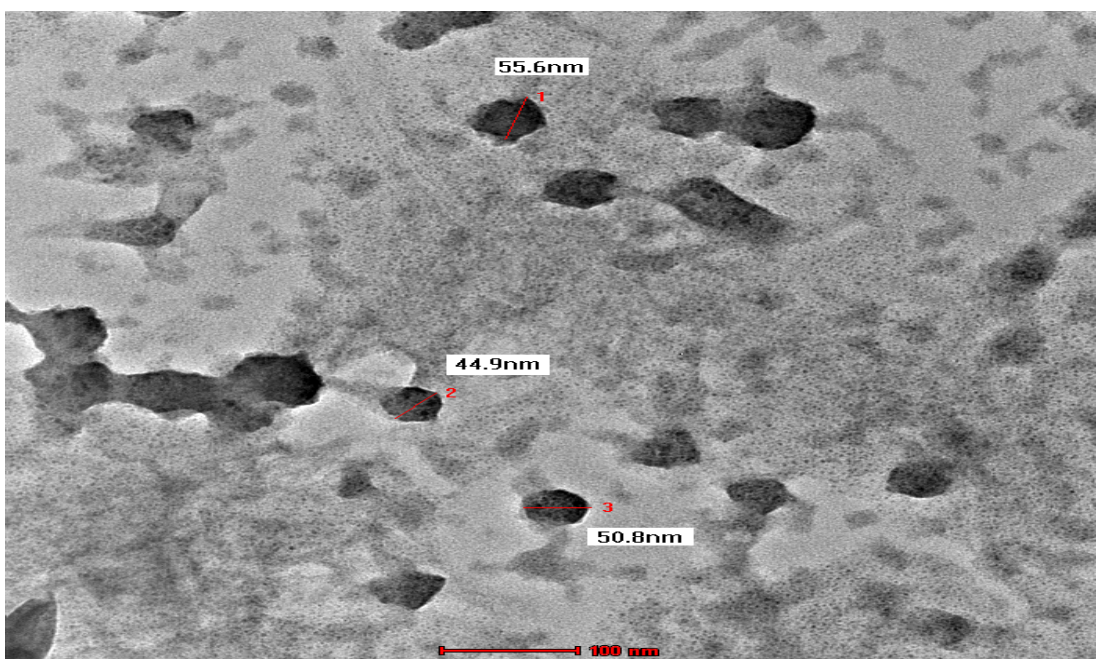

B

Fig. 7: TEM image obtained for the morphological and size analysis of lyophilized caffeine-loaded CS-NPs. A. 86000 magnification; B. 125 000 magnification

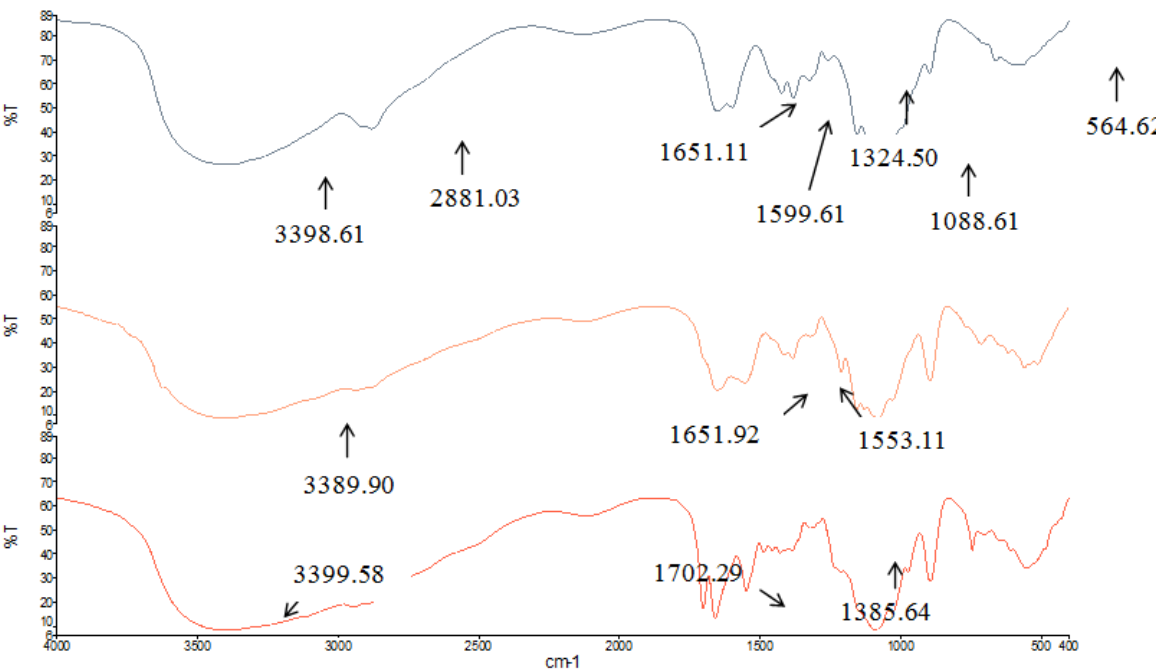

Fig. 8: FT-IR spectra of (a) CS, (b) unloaded CS-NPs, and (c) caffeine-loaded CS-NPs 


\section{FTIR and XRD analysis}

The FTIR spectra of low molecular CS, unloaded CS-NPs, and caffeine-loaded CS-NPs are shown in fig. 8. The results indicate that the intense characteristic peaks of CS (fig. 4(a)) appeared at 3398.61 $\mathrm{cm}^{-1}$ (-OH stretching), $2881.03 \mathrm{~cm}^{-1}$ (-CH stretching), $1651.11 \mathrm{~cm}^{-1}$, $1599.61 \mathrm{~cm}^{-1}$ (-NH2 stretching), $1324.50 \mathrm{~cm}^{-1}$ (C-N stretching), $1088.61 \mathrm{~cm}^{-1}$ (C-O-C stretching) and $564.62 \mathrm{~cm}^{-1}$ (pyranoside ring stretching vibration). The characteristic peaks of unloaded CS-NPs (fig. 4 (b)) representing- $\mathrm{OH}$ group appeared at $3389.90 \mathrm{~cm}^{-1}$. The$\mathrm{NH}_{2}$ bending vibration shifts from $1651.11 \mathrm{~cm}^{-1}$ and $1599.61 \mathrm{~cm}^{-1}$ to $1651.92 \mathrm{~cm}^{-1}$ and $1553.11 \mathrm{~cm}^{-1}$, which indicates that some interaction between $\mathrm{NH}_{3}{ }^{+}$groups of CS and TPP occurred within the nanoparticles [33]. For caffeine-loaded CS-NPs (fig. 4 (c)), the-OH peak $\left(3399.58 \mathrm{~cm}^{-1}\right)$ becomes broader, indicating that bonding action is enhanced because of the reaction between CS and caffeine [34]. A new peak appeared at $1702.29 \mathrm{~cm}^{-1}$ indicating carbonyl group $(\mathrm{C}=0)$ present in caffeine. In addition, the peak at 1324.50 $\mathrm{cm}^{-1}$ (C-N bending) in the CS spectra (fig. 4(a)) shifted to 1385.64 $\mathrm{cm}^{-1}$ in the caffeine-loaded CS-NPs spectra (fig. 4(c)). This indicates interaction between the $\mathrm{C}=0$ group of caffeine and the primary amide group of CS. Hence, these results indicate that caffeine was successfully loaded into the CS-NPs.

The crystal phase identification of the studied samples was carried out using X-ray diffraction (XRD). It is a non-destructive technique widely used for the characterization of crystalline materials. The X-RD of chitosan, unloaded CS-NPs and caffeineloaded CS-NPs were determined and shown in fig. 9. CS exhibit two characteristic peaks at $2 \theta$ of $10.7^{\circ}$ and $20.3^{\circ}$ (fig. 5(a)), indicating some degree of crystallinity, however the degree of crystallinity was less than its nanoparticle form (fig. 5(b)). Unloaded CS-NPs showed several sharp peaks at $2 \theta$ of $23.3^{\circ}$, $27.0^{\circ}$ and $28.6^{\circ}$ indicating a more crystalline nature of nanoparticles. And the characteristic peaks of caffeine-loaded CS-NPs exhibit sharp peak only at $2 \theta$ of $11.9^{\circ}$, indicating a degree of crystallinity which was less than the unloaded CS-NPs. This may be the result of caffeine existing as a molecular dispersion in the polymeric nanoparticles, which in turn reduces the apparent crystallinity structure of the compound [35].
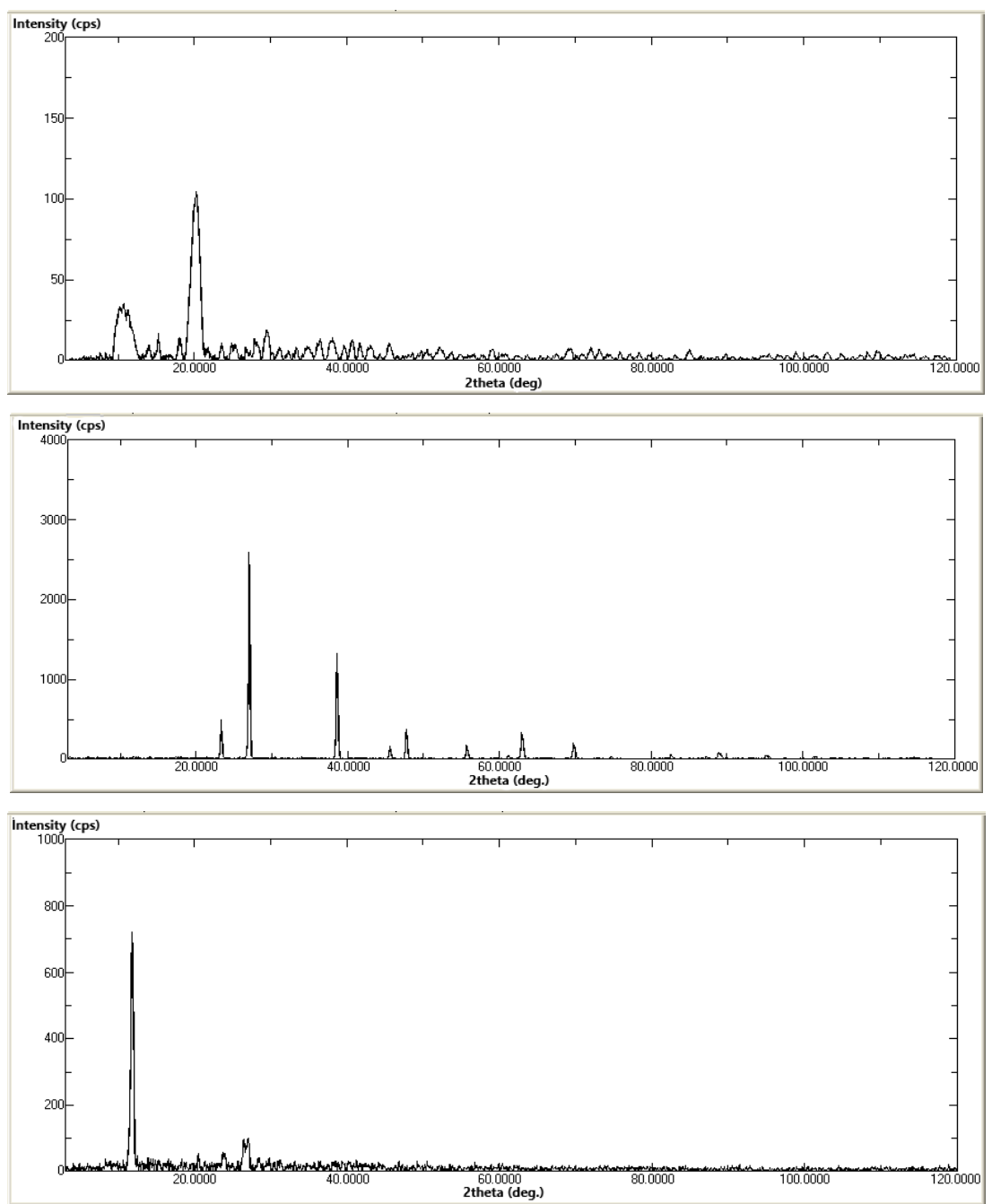

Fig. 9: XRD patterns of (a) CS, (b) unloaded CS-NPs and (c) caffeine-loaded CS-NPs

\section{Drug release studies}

The in vitro cumulative release profiles of caffeine from CS-NPs and aqueous solution of drug (control formulation) in PBS solution $(\mathrm{pH}$ 7.4) are depicted in fig. 10. There is an increment of drug release for both formulations within the $72 \mathrm{~h}$ duration of the study. Both formulations showed sustained release of caffeine throughout the $72 \mathrm{~h}$ duration. However, the release of caffeine from CS-NPs was significantly $(\mathrm{p}<0.001$, paired t-test) higher compared to the release of caffeine from control formulation. Within the first $8 \mathrm{~h}$ of study, caffeine released was $24.9 \%$ and $16.3 \%$ from CS-NPs and the control formulation respectively. At the end of $72 \mathrm{~h}$, approximately, $58.7 \%$ of caffeine was released from CS-NPs and $41.5 \%$ of caffeine was released from the control formulation. Caffeine-loaded in CS-NPs with a smaller size possess a greater surface-to-volume ratio, resulting in a higher released and penetration compared to caffeine in aqueous solution. In addition, drug release is less rapid in amorphous nanoparticles 
than in crystalline particles. Lack of crystallinity suggests better drug dispersion and increased drug-matrix interactions, leading to the conclusion that if slower release kinetics are required, reduced crystallinity is favoured [37].

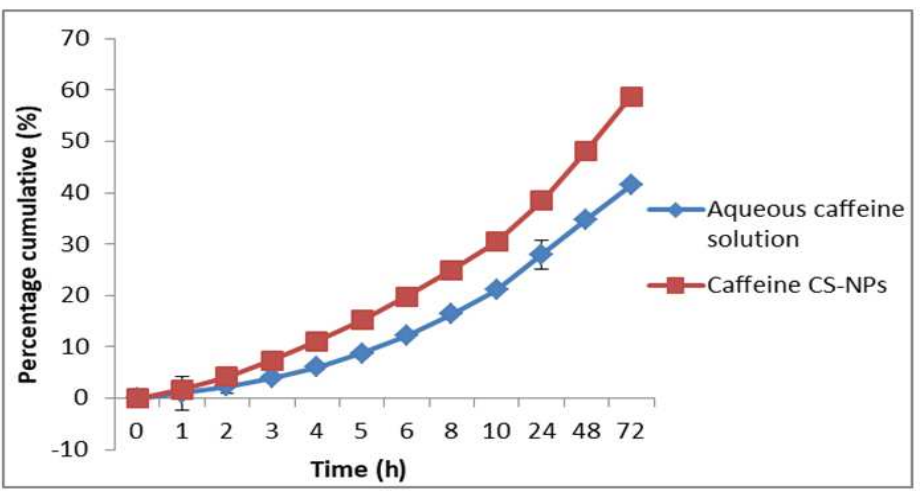

Fig. 10: Release profile of the caffeine from the caffeine-loaded CS-NPs formulation compared to an aqueous solution of the drug (control formulation), both containing $0.97 \mathrm{mg} / \mathrm{ml}$ of the drug. (mean $\pm S D, n=3$ )

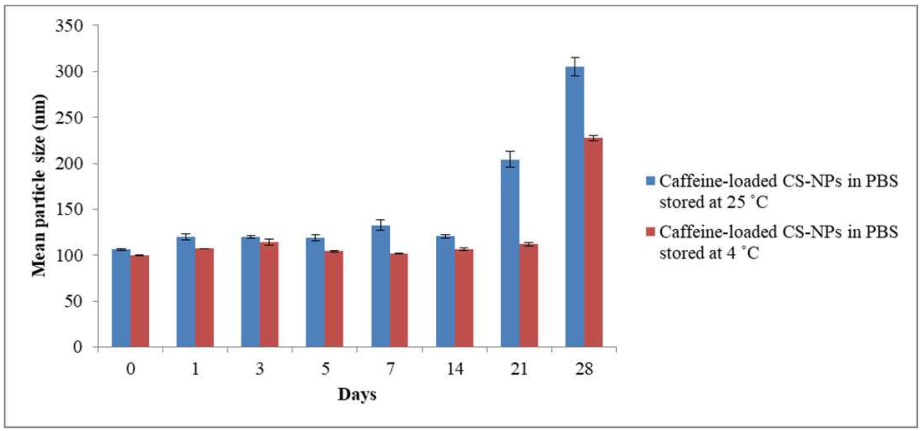

A

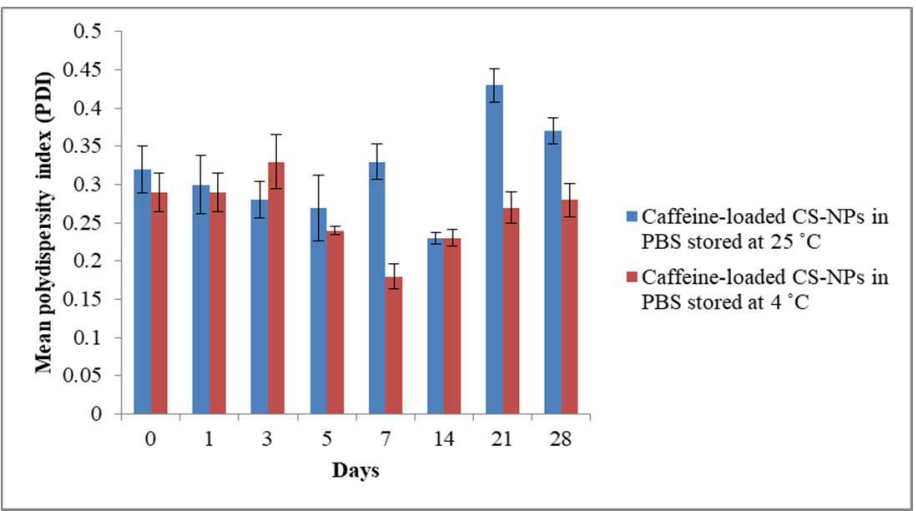

B

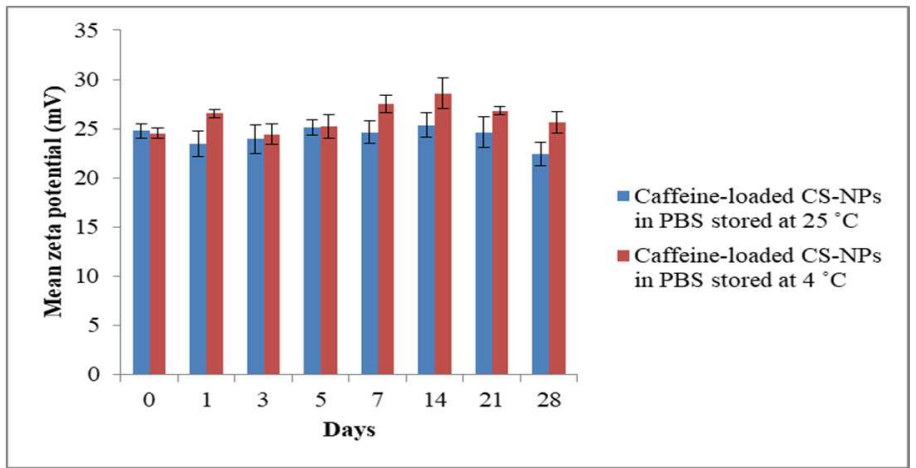

C

Fig. 11: Stability study on A. particle size; B. PDI; C. zeta potential of caffeine-loaded CS-NPs in PBS solution stored in solution at $25^{\circ} \mathrm{C}$ and $4{ }^{\circ} \mathrm{C}$ 


\section{Stability studies of nanoparticles in solution form}

Degradation times of CS-NPs loaded with caffeine in PBS stored at $25{ }^{\circ} \mathrm{C}$ and $4{ }^{\circ} \mathrm{C}$ observed over a $28 \mathrm{~d}$ period are shown in fig. 11. Particle sizes were measured as a function of time throughout the period. In both cases, particle sizes and standard deviations increased with time, similar to that described in previous studies [36]. The results also showed that the sample stored at room temperature degraded much quicker than that stored in the refrigerator. This increased in particle sizes may be due to particle agglomeration. However, the results obtained confirmed that the caffeine-loaded CS-NPs were stable throughout the $28 \mathrm{~d}$ period with the particle size, PDI and zeta potential remaining within the accepted nanoparticle range.

Stability studies of caffeine-loaded CS-NPs in freeze-dried form were also conducted at both temperatures for $28 \mathrm{~d}$. The results are shown in fig. 12. The mean particle size of caffeine-loaded CS-NPs shows much greater values, above $1000 \mathrm{~nm}$. Freezing exerts a substantial destabilizing stress on nanoparticles resulting in two phases of separation; one which contains ice and another concentrated viscous phase containing the nanostructures and other formulation constituents. This high particulate concentration, together with the ice crystals, may lead to aggregation, and in some cases, an irreversible fusion of nanoparticles [38, 39].

In addition, lyophilized caffeine-loaded CS-NPs showed instability as the zeta potential dropped to negative values when kept at both temperatures. Zeta potential of caffeine-loaded CS-NPs dropped from 5.60 to- $3.50 \mathrm{mV}$ within $2 \mathrm{~d}$ when kept at $4{ }^{\circ} \mathrm{C}$, and dropped from 5.60 to- $3.16 \mathrm{mV}$ at $25^{\circ} \mathrm{C}$ both within $14 \mathrm{~d}$ of the experiment. The decline in the zeta potential of caffeine-loaded CS-NPs was possibly due to of particle aggregation. Particle clumping may have occurred upon pelleting after centrifugation process. The aggregation in nanoparticles could be explained by electrolytes within the PBS solution, surrounding the nanoparticles reducing the surface charge of particles, hence reducing the ionic interaction between the ionized drug molecules and the positive charges on $\mathrm{CS}\left(-\mathrm{NH}^{3+}\right)$ molecules.

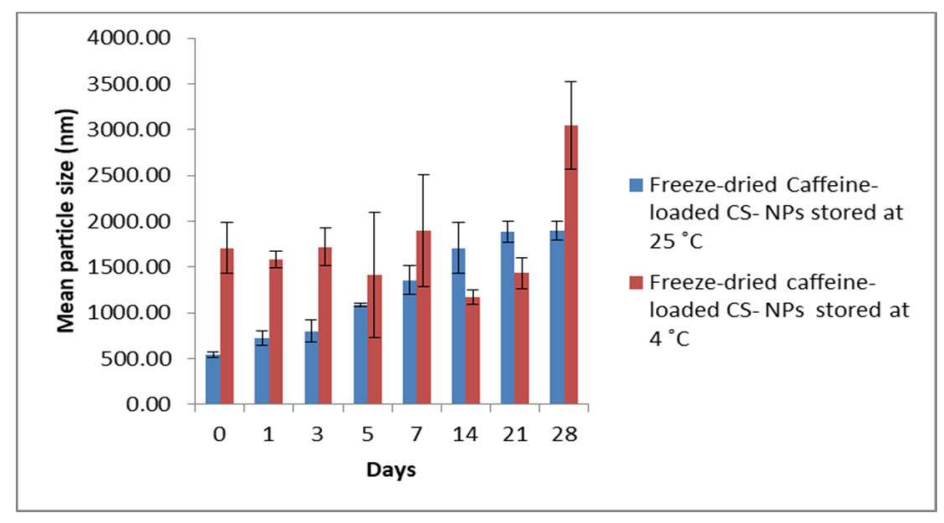

A
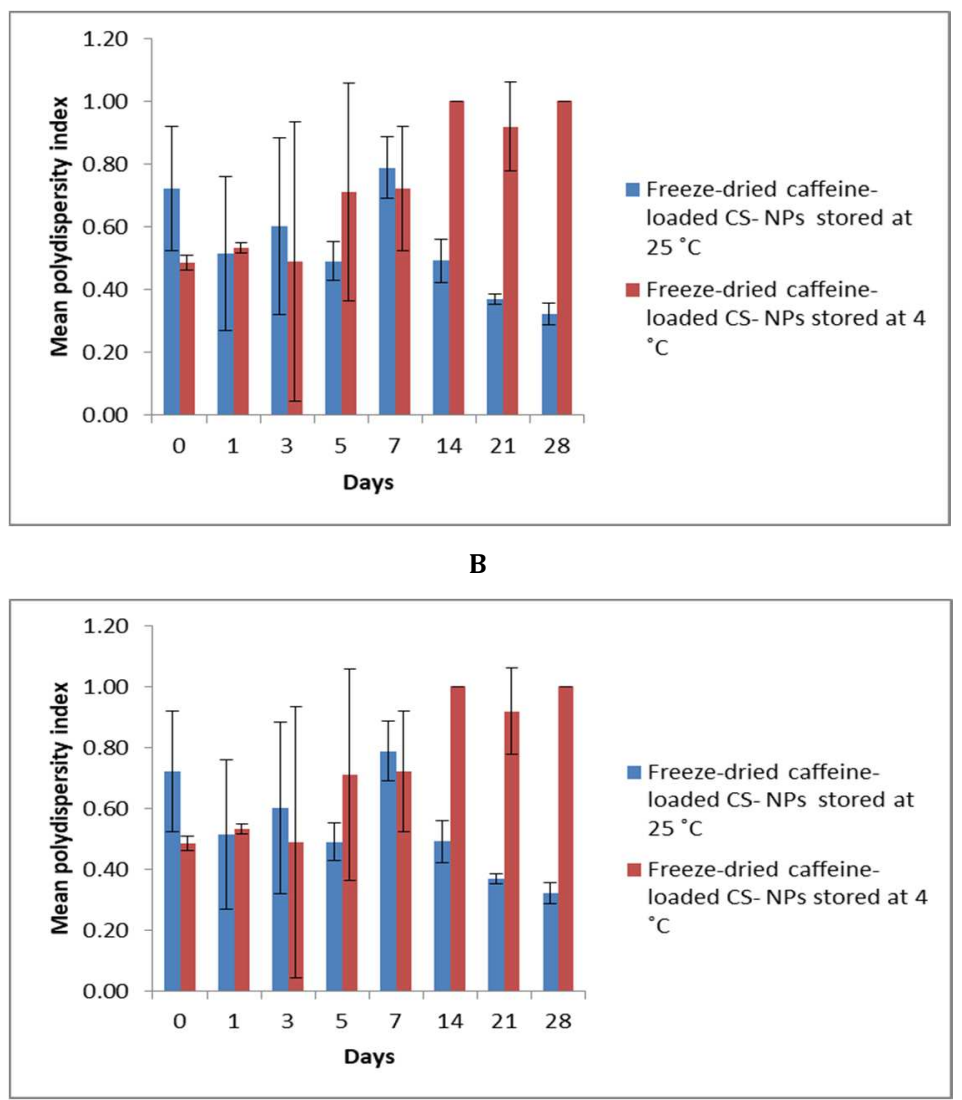

Fig. 12: Stability study on A. particle size; B. PDI; C. zeta potential of caffeine-loaded CS-NPs stored in freeze-dried form at $25{ }^{\circ} \mathrm{C}$ and $4{ }^{\circ} \mathrm{C}$ 


\section{CONCLUSION}

The current study demonstrated a significant influence of the preparation conditions (CS: TPP volume ratio, the concentration of the drug and stirring speed) on the mean particle size, zeta potential and polydispersity index of CS-TPP-NPs. The controlling parameters were clearly identified in this present study in order to produce CSTPP-NPs with optimal characteristics. The hydrophilic drug, caffeine was successfully incorporated in CS-NPs by cross-linking method with good EE (60.69\%) and LC (48.89\%). Caffeine-loaded CS-NPs was also found to release significantly more caffeine than the control formulation within the $72 \mathrm{~h}$ experiment duration. Finally, stability studies conducted for $28 \mathrm{~d}$ showed that caffeine-loaded CS-NPs degraded much quicker when stored at $25{ }^{\circ} \mathrm{C}$ than $4{ }^{\circ} \mathrm{C}$ and was more stable in solution than in its freeze-dried form.

\section{ACKNOWLEDGEMENT}

We would like to thank Institute of Research Management and Innovation (IRMI), UiTM for the funding of this study through Bestari Perdana grant, 600-IRMI/DANA 5/3/BESTARI(P) (002/2018).

\section{AUTHORS CONTRIBUTIONS}

All the author have contributed equally

\section{CONFLICT OF INTERESTS}

Declared none

\section{REFERENCES}

1. Randall VA, Thornton MJ, Hamada K, Redfern CP, Nutbrown M, Ebling FJ, et al. Androgens and the hair follicle: cultured human dermal papilla cells as a model system. Ann N Y Acad Sci 1991;642:355-75.

2. Omkar Hemant Lele, Jinesh Anant Maniar, Rohit Lalit Chakravorty, Shashikant Prabhakar Vaidya, Abhay Shadashiv Chowdhary. Assessment of biological activities of caffeine. Int J Curr Microbiol Appl Sci 2016;5:45-53.

3. Kim C, Shim J, Han S, Chang I. The skin permeation-enhancing effect of phosphatidylcholine: caffeine as a model active ingredient. J Cosmet Sci 2002;53:363-74.

4. Trauer S, Patzelt A, Otberg N, Knorr F, Rozycki C, Balizs G, et al. Permeation of topically applied caffeine through the human skin-a comparison of in vivo and in vitro data. Br J Clin Pharmacol 2009;68:181-6.

5. Nehlig A, Daval JL, Debry G. Caffeine and the central nervous system: mechanisms of action, biochemical, metabolic and psychostimulant effects. Brain Res Brain Res Rev 1992;17:139-70.

6. Fabricant DS, Farnsworth NR. The value of plants used in traditional medicine for drug discovery. Environ Health 2001;109 Suppl 1:69.

7. Dodd SL, Herb RA, Powers SK. Caffeine and exercise performance. Sports Med 1993;15:14-23.

8. Panchal SK, Poudyal H, Waanders J, Brown L. Coffee extract attenuates changes in cardiovascular and hepatic structure and function without decreasing obesity in high-carbohydrate, high-fat diet-fed male rats. J Nutr 2012;142:690-7.

9. Vogelgesang B, Bonnet I, Godard N, Sohm B, Perrier E. In vitro and in vivo efficacy of sulfo-carrabiose, a sugar-based cosmetic ingredient with anti-cellulite properties. Int J Cosmet Sci 2011;33:120-5.

10. Koo SW, Hirakawa S, Fujii S, Kawasumi M, Nghiem P. Protection from photodamage by topical application of caffeine after ultraviolet irradiation. Br J Dermatol 2007;156:957-64.

11. Kawasumi M, Lemos B, Bradner JE, Thibodeau R, Kim Y, Schmidt $\mathrm{M}$, et al. Protection from UV-induced skin carcinogenesis by genetic inhibition of the ataxia telangiectasia and Rad3-related (ATR) kinase. Proc Nat Acad Sci USA 2011. Doi:10.1073/pnas.1111378108.

12. Fischer TW, Hipler UC, Elsner P. Effect of caffeine and testosterone on the proliferation of human hair follicles in vitro. Int J Dermatol 2007;46:27-35.

13. Souto EB, Almeida AJ, Müller RH. Lipid nanoparticles (SLN®, NLC $®$ ) for cutaneous drug delivery: structure, protection and skin effects. J Biomed Nanotechnol 2007;3:317-31.
14. CL Fang, IA Aljuffali, YC Li, JY Fang. Delivery and targeting of nanoparticles into hair follicles. Ther Delivery 2014;5:991-1006.

15. GM Gelfuso, T Gratieri, PS Simao, LAP de Freitas, RFV Lopez Chitosan microparticles for sustaining the topical delivery of minoxidil sulphate. J Microencapsul 2011;28:650-8.

16. Huabing Chen, Xuelin Chang, Danrong Du, Wei Liu, Jie Liu, Ting Weng, et al. Podophyllotoxin-loaded solid lipid nanoparticles for epidermal targeting. J Controlled Release 2006;110:296-306.

17. Smijs TGM, Bouwstra JA. Focus on the skin as a possible port of entry for solid nanoparticles and the toxicological impact. J Biomed Nanotechnol 2010;6:469-84.

18. K Ziani, I Fernandez Pan, M Royo, JI Mate. Antifungal activity of films and solutions based on chitosan against typical seed fungi. Food Hydrocolloids 2009;23:2309-14.

19. E Marin, MI Briceno, C Caballero George. Critical evaluation of biodegradable polymers used in nanodrugs. Int J Nanomed 2013;8:3071-91.

20. Alvarez Roman R, Barre G, Guy RH, Fessi H. Biodegradable polymer nanocapsules containing a sunscreen agent: preparation and photoprotection. Eur J Pharm Biopharm 2001;52:191-5.

21. P Manimekalai, R Dhanalakshmi, R Manavalan. Preparation and characterization of ceftriaxone sodium encapsulated chitosan nanoparticles. Int J Appl Pharm 2017;9:10-5.

22. Lademann J, Richter H, Teichmann A, Otberg N, Blume Peytavi U, Luengo J, et al. Nanoparticles-an efficient carrier for drug delivery into the hair follicles. Eur J Pharm Biopharm 2007;66:159-64.

23. Colonna C, Conti B, Perugini P, Pavanetto F, Modena T, Dorati R, et al. Ex vivo evaluation of prolidase loaded chitosan nanoparticles for the enzyme replacement therapy. Eur J Pharm Biopharm 2008;70:58-65.

24. Calvo P, Remunan Lopez C, Vila-Jato JL, Alonso MJ. Novel hydrophilic chitosan-polyethylene oxide nanoparticles as protein carriers. J Appl Polym Sci 1997;63:125-32.

25. Huang Y, Lapitsky Y. Monovalent salt enhances colloidal stability during the formation of chitosan/tripolyphosphate microgels. Langmuir 2011;27:10392-9.

26. Yang HC, Hon MH. The effect of the degree of deacetylation of chitosan nanoparticles and its characterization and encapsulation efficiency on drug delivery. Polym Plast Technol Eng 2010;49:1292-6.

27. Thandapani, Supriya Prasad, Sudha, Sukumaran. Size optimization and in vitro biocompatibility studies of chitosan nanoparticles. Int J Biol Macromol 2017;104:1794-806.

28. Hussain Z, Sahudin S. Preparation, characterization, and colloidal stability of chitosan-TPP nanoparticles: optimization of formulation and process parameters. Int J Pharm Pharm Sci 2016;8:297-308.

29. Nie KB, Wang XJ, Wu K, Xu L, Zheng MY, Hu XS, et al. Processing, microstructure and mechanical properties of magnesium matrix nanocomposites fabricated by semisolid stirring assisted ultrasonic vibration. J Alloys Compd 2011;509:8664-9.

30. M Jahanshahi, AW Pacek, AW Nienow, A Lyddiatt. Fabrication by three-phase emulsification of pellicular adsorbent customized for liquid fludized bed adsorption products. Chem Technol Biotechnol 2003;78:1111-20.

31. B Ruan, AM Jacobi. Ultrasonication effects on thermal and rheological properties of carbon nanotube suspensions. Nanoscale Res Lett 2012;7:127.

32. Matos B, Reis T, Gratieri, Gelfuso. Chitosan nanoparticles for targeting and sustaining minoxidil sulphate delivery to hair follicles. Int J Biol Macromol 2015;75:225-9.

33. Xu YM, Du YM. Effect of molecular structure of chitosan on protein delivery properties of chitosan nanoparticles. Int J Pharm 2003;250:215-26.

34. Wu W, Yang W, Wang CC, Hu JH, Fu SK. Chitosan nanoparticles as a novel delivery system for ammonium glycyrrhizinate. Int J Pharm 2005;295:235-45.

35. Y Zhang, RX Zhu. Synthesis and drug release behavior of poly(trimethylene carbonate)-poly(ethylene glycol)-poly (trimethylene carbonate) nanoparticles. Biomaterials 2005;26: 2089-94.

36. T Lopez Leon, ELS Carvalho, B Seijo, JL Ortega Vinuesa, D Bastos Gonzalez. Physicochemical characterization of chitosan 
nanoparticles: electrokinetic and stability behavior. J Colloid Interface Sci 2005;283:344-35.

37. Paul Baldrick. The safety of chitosan as a pharmaceutical excipient. J Regul Toxicol Pharmacol 2010;56:290-9.

38. Yangchao Luo, Boce Zhang, Monica Whent, Liangli (Lucy) Yu, Qin Wang. Preparation and characterization of zein/chitosan complex for encapsulation of $\alpha$-tocopherol, and its in vitro controlled release study. Colloids Surf B 2011;85:145-52.
39. Yang Wei Wang, Chi Hsiung Jou, Chia Chun Hung, Ming Chien Yang. Cellular fusion and whitening effect of a chitosan derivative coated liposome. Colloids Surf B 2012;90:169-76.

40. Raditya Iswandana, Kurnia Sari Setio Putri, Randika Dwiputra, Tryas Yanuari, Santi Purna Sari, Joshita Djajadisastra. Formulation of chitosan tripolyphosphate-tetrandrine beads using ionic gelation method: in vitro and in vivo evaluation. Int Appl Pharm 2017;9:109-15. 